\title{
Rusmiddelbruk og selvmord
}

Ved Nils Retterstøl

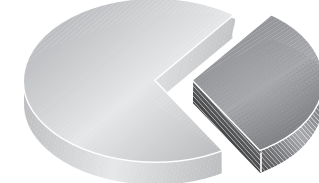

Ca $1 / 3$ av dem som tar sitt eget liv er avhengig av alkohol eller andre vanedannende stoffer

\section{Det er et velkjent fenomen at det er en sterk sammenheng mellom bruk av rusmidler (alkohol og andre vanedannende stoffer) og selumord.}

\section{Rusmiddelproblemer hos dem som tar sitt liv}

Den internasjonale litteraturen er entydig: En relativt stor prosent, omkring tredjeparten av dem som tar sitt liv, har hatt så svære problemer med alkohol og stoff at de er å regne som alkohol- eller stoffmisbrukere.

Den første systematiske studien som bekrefter dette, stammer fra USA: Robins og medarbeidere (1959) samlet inn data vedrørende alle registrerte selvmord i et bestemt opptaksområde, og senere kartla de hvert tilfelle ved såkalt "psykologisk autopsi", personlig samtale med de etterlatte. Dorpat og Ripley (1960) i USA fulgte opp og fant at $31 \%$ misbrukte alkohol eller stoff.

Med "psykologisk autopsi" kartla Beskow (1979) et større svensk materiale av selvmordere og fant at 31\% var alkoholmisbrukere (39 \% i byområdene og 18 \% i landlige områder). Hagnell og Rorsmann (1979) fant i sitt materiale omtrent samme prosent som Beskow, men prosenten $\varnothing$ kte til 39 da stoffmisbrukere ble inkludert. Situasjonen er også kartlagt i vårt land. Alle selvmord i Oslo blant personer i alderen 15-29 år i to syvårsperioder ble kartlagt av Retterst $\varnothing$ l og medarbeidere $(1985,1993)$. I deres materialer var om lag tredjeparten avhengig av alkohol eller vanedannende stoffer, og halvparten hadde alkoholpromille i blodet på selvmordstidspunktet. At såpass mange har alkohol i blodet, forklares slik at en del mennesker "drikker seg til mot" for å foreta en så drastisk og ugjenkallelig handling.

Det er hos menn overvekten av alkoholmisbruk er størst. Åsgård (1990) uførte en grundig unders $\varnothing$ kelse av selvmord hos kvinner i Stockholm, og fant at $16 \%$ var å regne som alkoholikere.

Viktig å merke seg er at depressive lidelser forekommer samtidig hos en meget stor del av de alkohol- og stoffmisbrukere som tar sitt liv, i de refererte arbeider hos 30-70 \%. En kombinasjon av diagnosen alkohol- og/eller stoffmisbruk og depresjon er således meget alvorlig med hensyn til senere selvmord. Depresjonsdiagnosen har lett for å bli oversett, dels fordi man konsentrerer seg om rusproblemene, som umiddelbart er mest påfallende, og dels fordi pasientene, særlig mennene, ikke kommer frem med sine depressive tanker og følelser hvis legen eller behandleren ikke spør nærmere om depresjon. En depresjonstest, som MADRS, kan være et verdifullt hjelpemiddel i tillegg til en grundig samtale og klinisk kartlegging.

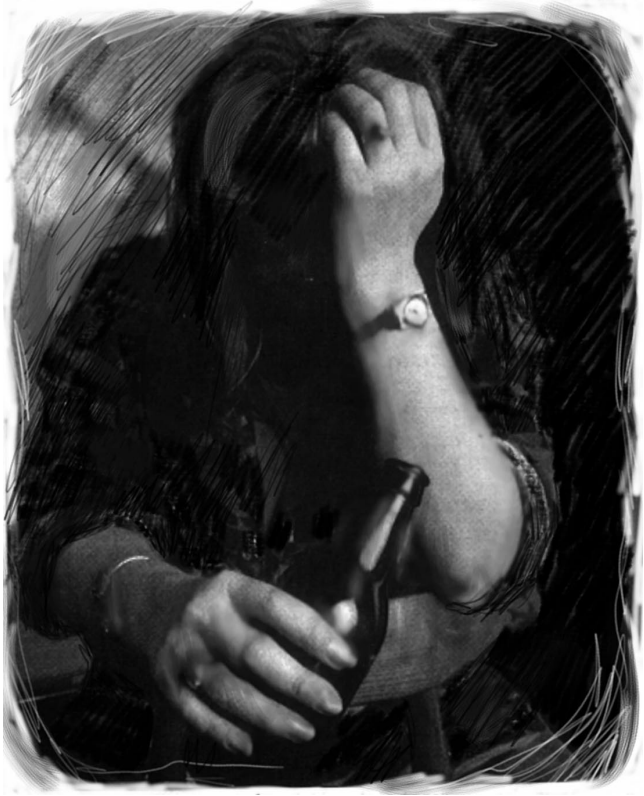

\section{I hvilken utstrekning foretar rusmisbrukere selvmord?}

Dette spørsmålet har vært inngående belyst. Sundby (1967) fant i et større materiale av pasienter som var sykehusbehandlet for alkoholisme, at forholdstallet mellom suicid i denne gruppen og forventet suicid i befolkningen ellers etter 30 år var ca 8. Dette tallet samsvarer godt med tilsvarende tall fra Tyskland: 8.75 (Feuerlein 1975). Rossow og Amundsen (1995) fant forholdstallet 5 hos menn som var behandlet i ulike behandlingsenheter, og de fant at hver 20. mannlige alkoholmisbruker endte sitt liv i selvmord.

I et større materiale av stoffmisbrukere i Sverige fant Lindberg og Ramström (1977) en dødelighet som var 11 ganger høyere enn forventet, og en dødelighet av selvmord som var 30 ganger høyere enn forventet.
I sitt allerede klassiske arbeid over selvmord og alkoholisme gjennomgikk Murphy (1992) verdenslitteraturen over alkoholisme og selvmord. Han brakte inn en ny måte å betrakte tallene på. Bare $25 \%$ av befolkningen i USA får i løpet av livet en identifiserbar psykiatrisk diagnose. $95 \%$ av alle selvmord finner sted i den gruppen som har en psykiatrisk diagnose. Sammenlignet med den gruppe som ikke har en psykiatrisk diagnose, fant han da at alkoholikerne som gruppe har en 115 ganger høyere selumordsrisiko enn mennesker som ikke har fått en psykiatrisk diagnose.

Ut fra norske materialer vet vi at risikoen for å d $\varnothing$ i selvmord er mer enn 15 ganger så stor som i befolkningen ellers, dersom man er oppført i landets register for alkoholistomsorgen. Sammenligner man med den del av befolkningen som ikke har fått noen psykiatrisk diagnose i løpet av livet sitt, er det mulig at de norske tallene kommer opp i tilsvarende $\varnothing$ kte risikoverdier som Murphy's.

Stoffmisbrukere har en meget høy selvmordsrisiko, som tidligere nevnt i et svensk materiale, 30 ganger høyere enn forventet. Danske unders $\varnothing$ kelser har vist at $5-6 \%$ av de unge pr. år slutter å bruke stoff, mens $2 \%$ dør.

\section{Har alkohol betydning for selvmordshyppigheten?}

Dette spørsmål er søkt kartlagt i den tidligere Sovjetunionen av Wasserman og medarbeidere $(1994,1998)$. Regresjonsanalyse med alkoholforbruk som den uavhengige variabel og selvmordshyppighet og $d \varnothing d$ av voldshandlinger som avhengige variabler viste klart at selvmord og alkoholforbruk var positivt korrelert, slik også voldsd $\varnothing$ deligheten og alkoholforbruk var. I republikker med høyt alkoholforbruk (de slaviske og baltiske) var det høyere selvmordsrater, i de kaukasiske med lavt alkoholforbruk lave selvmordsrater. For de fleste republikker synes det som alkohol kunne "forklare" mer enn halvparten av selvmordene. Deres materiale skriver seg fra årene 1984 til 1996, og gjelder begge kjønn. 


\section{Selvmordsforsøk og rusmidler}

Selvmordsfors $\varnothing \mathrm{k}$ er også mer vanlig blant rusmiddelmisbrukere enn i befolkningen ellers. I et gresk arbeid (Kokkevi og medarbeidere 1997) er det vist at selvmordsfors $\varnothing \mathrm{k}$ er syv ganger høyere for gutter som bruker stoff og fem ganger høyere hos piker som bruker stoff, enn blant tilsvarende ikke-stoffmisbrukere. Dette var for unge i alderen 14-18 år. Blant voksne er de tilsvarende tall 19 og 5 . Hos stoffmisbrukere av opiater rapporterte $27 \%$ at de hadde gjort selvmordsfors $\varnothing \mathrm{k}$ mot 0,5\% i tilsvarende kontrollgruppe, med andre ord en 54 ganger høyere hyppighet.

\section{Hvorfor er selvmord så hyppig?}

Det er rimelig at selvmord og -fors $\varnothing \mathrm{k}$ er hyppigere hos rusmiddelmisbrukere enn hos folk flest. Gjennom misbruket bringes man ut i mange flokete livssituasjoner. Nære kontakter ryker; ekteskap, familieliv, arbeid. Sosial degradering følger, likeså tap av selvfølelse og verdighet: skilsmisse, mangelfull kontakt med familien, brutte familie- og vennskapsbånd, arbeidsløshet, skoletap, flytting, ofte til stadig dårligere forhold: hybel, herberge, $\varnothing$ konomiske problemer. Nettverket rakner, og fors $\varnothing \mathrm{k}$ på å etablere nytt blir gjerne med mennesker i tilsvarende situasjon, som kanskje bare forsterker den negative selvfølelsen som er utviklet. De unge rusmiddelmisbrukere har falt ut av samfunnet så tidlig at de ikke er kommet i arbeid enda, men bare har rukket å bli skoletapere og problemungdom som føler seg mislykket sammenlignet med ungdom flest.

Men den høye selvmordshyppigheten henger nok også sammen med seleksjonsfaktorer. De samme personlighetsfaktorer som disponerer for flukt fra livsproblemer med rusmidler, kan også disponere for flukt fra det samme gjennom selvmordsfors $\varnothing \mathrm{k}$ og selvmord. Den f $\varnothing$ lelsesmessige umodenheten som ofte preger den som ikke har kontroll over rusproblemer, preger også mange av dem som "velger" selvmordsfors $\varnothing \mathrm{k}$ eller selvmord som løsning på kompliserte livsproblemer.

Dessuten blir kontrollmekanismene svekket under innflytelse av rusmidler, normale bremsemekanismer blir ikke mobilisert.

\section{Spesielle risikofaktorer}

De samme risikofaktorer som gjelder for selvmord, gjelder også for alkoholavhengige. Murphy (1992) har i sitt meget grundige arbeid identifisert syv særlig viktige risikofaktorer:

- Aktiv drikkeperiode. All erfaring viser at dersom alkoholmisbruken stoppes og avhold etableres, blir risikoen mindre.

- Alvorlig depressiv lidelse. Alvorlig depresjon hos en alkoholavhengig er den tilleggsfaktor som $\varnothing$ ker selvmordsrisikoen mest

- Liten eller ingen sosial st $\varnothing$ tte, mangel på nettverk, støttepersoner og kontrollpersoner

- Arbeidsløshet, spesielt langtidsarbeidsløshet

- Alvorlig legemlig lidelse

- Bor alene (hybel, herbergetilværelse, uteligger)

- Meddelelse om selvmordstanker og planer.

Som regel er flere av disse faktorer til stede samtidig. Er 4 av disse 7 faktorer til stede, vil man ha identifisert fire femdeler av dem som er $i$ høyeste risikogruppe.

Stort sett gjør de samme forhold seg gjeldende ved stoffmisbruk. Her kan det tilføyes at sprøytenarkomane har en høyere selvmordsrisiko enn andre, og at de som misbruker heroin, amfetamin og kokain er særlig utsatt. Langvarig misbruk og forkommenhet $\varnothing$ ker risikoen. Overdosed $\varnothing$ dsfall ser man hyppigst ved heroinmisbruk (ca 130 tilfeller i 1998 bare i Oslo). Men overdosed $\varnothing$ dsfall er i seg selv ikke å regne som selvmord. Det er ofte tilfeldige omstendigheter som gjør at utfallet av sprøyten blir dødelig, f.eks. samtidig inntak av andre vanedannende stoffer som forsterker virkningen av heroin.

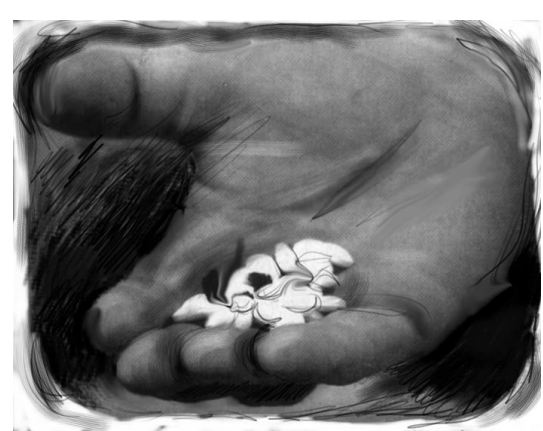

\section{Hva kan gjøres forebyggende og behandlingsmessig?}

Her er svaret: meget. Dette gjelder både på det primære, sekundære og tertiære forebyggende plan. Det vil naturligvis innen denne lille artikkels ramme ikke være mulig å summere opp alle relevante tiltak. Den interesserte vil finne oversikter i mine bøker Stoffmisbruk (1987), Selvmord (1995) og i den nasjonale handlingsplan (1995). Men av denne artikkelen håper jeg det fremgår at det er nødvendig med en grundig somatisk og psykiatrisk screening av alle rusmiddelmisbrukere. Der er så mange medisinske, somatiske og psykiatriske faktorer til stede hos rusmiddelmisbrukere at ingen $b \varnothing r$ komme i et behandlingsopplegg f $\varnothing \mathrm{r}$ de er grundig medisinsk unders $\varnothing \mathrm{kt}$. Noe av det viktigste vil være å påvise om en samtidig depresjon er tilstede. Denne kan avhjelpes ved psykoterapi, sosialterapi etc., men vil i mange tilfelle bedres best ved samtidig antidepressiv medikamentell behandling i adekvate doser og som regel over lang tid, utover depresjonens varighet. I noen tilfeller vil elektrokonvulsiv behandling kunne være livreddende. Hos om lag $10 \%$ av de unge stoffmisbrukere foreligger en schizofreni, og i denne kombinerte dobbeltdiagnosegruppe er selvmordshyppigheten særdeles høy. Heldigvis etableres nå etter hvert egne avdelinger for pasienter med dobbeltdiagnoser, som i noen grad har falt utenfor både innen stoffmisbruksomsorgen og det psykiatriske behandlingsapparat.

Psykiatriske avdelinger har, ettersom stoffmisbrukerne ble definert utenfor helsevesenet, hatt en tilbøyelighet til avvisende holdninger overfor denne gruppen, mens rusmiddelomsorgen har hatt en tilsvarende holdning til pasienter med psykiatrisk symptomatologi. Både alkohol- og stoffmisbrukere hører gjerne hjemme i begge omsorgsgrupper. Etter min mening har det vært uheldig med en særomsorg, som har vært med på å lage kunstige skillelinjer og hindret grupper av mennesker i å få riktigere diagnoser og derved bedre behandling. 


\section{forts. fra forrige side}

Disse er også omtalt i boken Selvmord (Retterstøl 1995). I Norge har man i enkelte byer og tettsteder egne opplegg for mennesker som har mistet sine i selvmord. Foruten fra helsetjenesten, kan hjelp gjerne gis fra de enkelte menigheter. Det er et klart behov for bedre behandlingsopplegg for denne vanskeligstilte gruppe av mennesker. En egen landsoversikt over sorggrupper, deriblant sorggrupper for etterlatte etter selvmord, fins på Internettsidene til Seksjon for selvmordsforskning og -forebygging, under Etterlatte.

\section{Avslutning}

Dette nummer av tidsskriftet vårt er viet psykiatriske lidelser, og denne artikkelen har satt fokus på forebyggende tiltak mot selvmord i denne pasientgruppen. Vi har konsentrert oss om problemer og svikt i behandlingsopplegget. Artikkelen har derved i utgangspunktet en negativ slagside. Men la oss ikke glemme det entusiastiske og slitsomme arbeidet som utføres av de mange helsearbeidere, og den påkjenningen arbeidet med suicidale pasienter er for de fleste av oss. Det krever mye av oss som mennesker og medmennesker, og kan være med å gi noen og hver utbrenthetssyndrom. Men arbeidet innebærer også mange gleder og oppmun- tringer. Vi trenger imidlertid "påfyll” skal vi holde ut. Slikt påfyll får vi fra takknemlige pasienter vi hjelper et stykke på vei, - og vi får det ved opplæringsprogrammer, veiledning, kollegialt samarbeid og ved kompetanseheving.

Selv om det ikke alltid slår til, er vår rettesnor: Selvmord kan forebygges.

\section{Litteratur:}

Berntsen G, Husby R: Behandling av selvmordsfors $\phi$ kere i en somatisk avdeling.

Tidsskr. Nor. Lægeforen. 1994; 114: 2374-2378

Burmo M, Borg SE, Dieserud G, Sveum BD: Selvmordsfors $\phi k$ i Bærum 1984-1988. Rapport om det oppf $\varnothing$ lgende arbeid etter selvmordsfors $\phi k$ i Bærum kommune.

Bærum kommune: Helseetaten, 1990

Dieserud G, Mathiesen KS, Dalgard OS: Veileder: selvmordsforebyggende arbeid: Bærumsmodellen Oslo: Senter for sosialt nettverk og helse, 1993

Dunne EJ: Following a suicide postvention.

I: Bongar B: Suicide, guidelines for assessment, management, and treatment.

New York: Oxford University Press, 1992

Prosjektplan og handlingsplan mot selvmord 1994-1998. Skriftserie 4-95.

Oslo: Statens helsetilsyn, 1995

Ramon S, Bancroft HJ, Shirmshire M: Attitudes towards self-poisoning among physicians and nurses in a general hospital Br. J. Psychiatry 1975; 127: 257-264

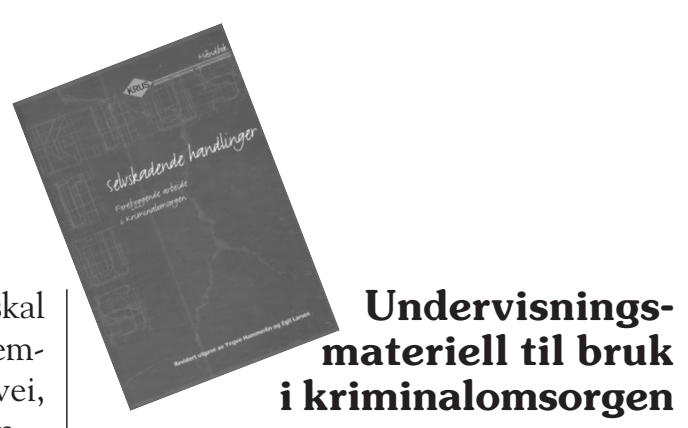

Hammerlin, Yngve / Larsen, Egil

Selvskadende handlinger.

Forebyggende arbeide i kriminalomsorgen. Håndbok.- rev utg. Oslo: KRUS - Kriminalomsorgens utdanningssenter, 1998. - $50 \mathrm{~s}$.

Manual. Underlag for klientsamtaler ved forebygging av selvskadende handlinger

Kortversjon. Selvmord(fors $\varnothing \mathbf{k}$ ) og selvbeskadigelse. En forenkling av håndboka/ en folder som kan puttes i skjortelomma.

Undervisningssettet kan bestilles fra KRUS v/Turid Midtbø, Pb 6138 Etterstad, 0602 Oslo, tlf: 230671 00, faks: 23067102.

(Omtale i neste nummer)

Retterst $\varnothing 1$ N: Selvmord

Oslo: Universitetsforlaget, 1995

Runeson B, Wasserman DW, Träskman-Bendz L, Agren H, Asberg M: Management of suicide attempters in psychiatric care in Sweden. Nord. J. Psychiatry 1994, 48: 117-120

Shneidman, Edwin S. The death of man. New York: Quadrangle Books, 1973

Wasserman DW: Attempted suicide - the patients' family, social network and therapy. Akademisk avhandling. Stockholm: Karolinska institutet, 1986

Robins E, Gassner S, Kayes J, Wilkinson RH, Murphy GE: The communication of suicidal intent: a study of 134 consecutive cases of successful (completed) suicide.

Am. J. Psychiatry 1959; 115: 724-733

*Rossow I, Amundsen A: Alcohol abuse and suicide: a 40-year prospective study of Norwegian conscripts. Addiction 1995; 90: 685-691

Sundby P: Alcoholism and mortality Oslo: Universitetsforlaget, 1967

Wasserman D, Värnik A, Eklund G: Female suicides and alcohol consumption during perestroika in the former USSR

Acta Psychiatr. Scand 1998; 98 (suppl 394): 26-33

Wasserman D, Värnik A, Eklund G: Male suicides and alcohol consumption in the former USSR Acta Psychiatr. Scand 1994; 89: 306-313

Åsgård U: Suicide among Swedish women. A psychiatric and epidemiological study. Stockholm: Karolinska Institutet, 1990

*Ingeborg Rossow har skrevet artikkelen "Alkohol og selvmord" $i$ et tidligere nr. av dette tidsskriftet, som den interesserte leser henvises til: Rossow I: Alkohol og selvmord.

Nytt i suicidologi 1997; 1: 12-14 